\title{
Neurocognition in Congenital Central Hypoventilation Syndrome: influence of genotype and ventilation method
}

\author{
Ha Trang ${ }^{1,2^{*}} \mathbb{D}$, Pauline Bourgeois ${ }^{1}$ and Fawzia Cheliout-Heraut ${ }^{1}$
}

\begin{abstract}
Background: Congenital Central Hypoventilation Syndrome (CCHS) is characterized by central hypoventilation due to abnormal autonomic control of breathing and global dysautonomia. Patients harbour heterozygous PHOX-2B gene mutations which are polyalanine repeats of various lengths in most of the cases. A few previous studies have reported learning difficulties and neuropsychological disorders in patients with CCHS. The aims of the present study were (1) to explore the intellectual abilities of a group of children with CCHS followed up in the centre of reference for CCHS in France using the Wechsler batteries of tests, (2) and to assess whether there was any association between CCHS characteristics and various domains of the intellectual functioning.

Results: There were 34 consecutive patients (15 males, 19 females) of mean (SD) age of 7.8 (3.8) years, ranging from 4 to 16 years and 6 months. Mean score of full-scale intelligence quotient was 82 (20), being in the low average range. Indexes of working memory and processing speed were significantly lower as compared to the other Wechsler indexes. There were two important findings: (1) full-scale intelligence quotient as well as indexes of verbal comprehension and processing speed were significantly greater in patients with mask ventilation than in those with tracheostomy ventilation ( $p=0.012,0.032$ and 0.042 respectively); ( 2 ) most interestingly, in the patients with polyalanine repeats mutations, all intellectual indexes negatively correlated with the number of polyalanine expansion, with statistical significance reached for indexes of fluid reasoning and working memory $(R=-0.449, p=0.032$ and $R=-0.562, p=0.012$ respectively).

Conclusions: $C \mathrm{CHS}$ increased the risk to develop neurocognitive deficiencies, affecting particularly speed of processing and working memory. Our results suggested that both genetics and ventilation method could be also involved in the physiopathology of neurocognitive impairment. Further investigations were required to untangle the complex underlying processes. Neurocognitive assessments should be performed regularly in children with CCHS in order to plan re-education programs, adapt school integration and improve quality of life.
\end{abstract}

Keywords: Autonomous nervous system, Congenital Central Hypoventilation Syndrome, Neurocognition, PHOX-2B, Processing speed, Working memory

\footnotetext{
${ }^{*}$ Correspondence: ha.trang@aphp.fr

${ }^{1}$ Centre de référence de Maladies Respiratoires Rares Syndrome

d'Ondine, Hôpital Universitaire Robert Debré, 48 Boulevard Sérurier, 75019 Paris, France

Full list of author information is available at the end of the article
}

\section{Introduction}

Congenital Central Hypoventilation Syndrome (CCHS) is a rare condition of central hypoventilation due to abnormal autonomic control of breathing and global dysautonomia $[15,28]$. The incidence has been estimated to be at $1 / 148,000-1 / 200,000$ live births and the prevalence at $1 / 500,000$ individuals $[23,26]$. CCHS manifests at birth original author(s) and the source, provide a link to the Creative Commons licence, and indicate if changes were made. The images or other third party material in this article are included in the article's Creative Commons licence, unless indicated otherwise in a credit line to the material. If material is not included in the article's Creative Commons licence and your intended use is not permitted by statutory regulation or exceeds the permitted use, you will need to obtain permission directly from the copyright holder. To view a copy of this licence, visit http://creativecommons.org/licenses/by/4.0/. The Creative Commons Public Domain Dedication waiver (http://creativeco mmons.org/publicdomain/zero/1.0/) applies to the data made available in this article, unless otherwise stated in a credit line to the data. 
in most of the cases, but may also present later during childhood and even adulthood. Patients exhibit severe alveolar hypoventilation and central apnoeas, mainly during sleep, due to abnormally reduced or absent ventilatory responses to hypercapnia and hypoxia. CCHS may be isolated or associated with other dysautonomiarelated conditions such as Hirschsprung disease or neural crest tumours [28]. Mutations of the paired like homeobox $2 \mathrm{~b}$ gene $(P H O X-2 B)$ are found in most patients. The most frequent mutation is a heterozygous duplication of tracts of different lengths of the polyalanine stretch in the exon 3 (polyalanine repeat mutations, PARM). The number of repeats is normally set at 20 repeats, but may be expanded to 24 to 33 repeats on the affected allele in patients with CCHS $[1,21]$. The length of PA expansion has been suggested to be associated with severity of autonomic dysfunction and severity of respiratory deficiency in CCHS [13]. Less common are non-PARMs (NPARMs) including missense, nonsense and frameshift mutations. Lifetime assisted ventilation and close multidisciplinary care allow the patients to have a good quality of life [9].

Neurodevelopmental and cognitive outcomes are of increased concern in CCHS [4, 9, 14, 16, 20, 22, 24, 29, 30]. However, only a few data are available. Most studies showed a high variability in the developmental and adaptive functions of the patients in their daily life. Patients had significant difficulties in the mental functions of control over motor and emotional events at the body level. Motor and speech delays were frequently reported. Also, the burden of social interactions with health services or educators along with the disease course often resulted in uncomfortable situations and was thought to limit the patients' personal achievement [16]. Although most children attended regular schools, many had learning difficulties resulting in poor academic achievement.

A few studies showed that patients with CCHS had a wide range in intellectual indices with the Full-scale IQ being in the normal or low average range $[9,20,30]$. Attention and concentration disorders were highlighted, as well as visual/auditory memory disorders. A variety of domains were affected such as language, spatial perception, memory and executive functioning. A slow cognitive processing has been identified in one-third of the patients in an early study [24]. Mental and motor development were found normal in preschool children with PHOX2B 20/25 genotype and delayed in those with 20/26 and 20/27 [4]. However, these differences have not been confirmed by the same authors when they investigated school-age children with CCHS of their cohort [30]. Because recurrent hypoxia and hypercapnia are known factors that may negatively impacted brain development in the first years of life, this has lead many authors to recommend close monitoring of respiration and ensuring the best quality of oxygenation and ventilation in the patients.

The aims of the present study were to explore the intellectual abilities of a group of patients with neonatal and childhood CCHS followed up in the Centre of reference for CCHS in France and to assess whether there was any association between CCHS characteristics and various domains of the intellectual functioning.

\section{Methods}

\section{Participants}

The study group is composed of 34 consecutive patients with CCHS, aged from 4 to 16 years and 6 months at the time they underwent neurocognitive testing between March 2018 and October 2019. Patients originated from various parts of France and were admitted for clinical assessments in the national Center of reference for CCHS, University Hospital Robert Debré, Paris. Sociodemographic data, genetic data and medical history were reviewed. In addition to the CCHS-related assessments, neurocognitive testing was performed as recommended in routine care of all patients with CCHS in order to diagnose developmental and learning disorders. All parents gave their informed consent to publication of results in an aggregated form.

\section{Procedure and instruments}

The patients were assessed by a licensed clinical neuropsychologist. All the testing was performed in the same period of the day, i.e. early afternoon. All patients were in good health; they spontaneously breathed room air during the procedure and wore corrective glasses or lenses if needed. The Wechsler battery of tests was used to assess intelligence efficiency and general cognitive capacities: the Wechsler for Preschool and Primary Scale for Intelligence test version IV (WPPSI-IV) was used for children younger than 6 years and the Wechsler Intelligence Scale for Children test version V (WISC-V) for those who were older. The battery of tests consisted of subtests that aim to assess specific cognitive abilities. Subtest scores scaled from 1 to 19 (knowing that the general population had a mean score of 10 and a standard deviation (SD) of 3). They were summed and converted to the Full-scale IQ (FSIQ) that represented the child's general intellectual ability, as well as to five main primary index scores, each of them representing the abilities in discrete cognitive domains. In brief, Verbal Comprehension Index (VCI) mainly measured the ability to understand and retain verbal information (crystallized intelligence), to express and categorize; Visuo-Spatial Index (VSI) measured the ability to understand spatial relationships; Fluid Reasoning Index (FRI) measured the ability to reason and create new links (fluid intelligence); Working Memory Index 
(WMI) measured the ability to retain and process new information, and Processing Speed Index (PSI) measured speed of information processing. Each of these scores was set to have a mean of 100 and a SD of 15 for the general population.

\section{Statistical analyses}

SPSS version 22 (IBM SPSS, NY, USA) was used for analyses. Data were given as means and SD for quantitative variables and absolute values for qualitative variables. The hypothesis of normality was tested using Kolmogorov-Smirnov and Shapiro-Wilk tests. Differences in continuous variables between groups were tested using the Student's $t$ test for paired samples or one way ANOVA with Tukey's HSD post hoc tests where appropriate. In addition, as the length of polyalanine expansion is thought to be associated with the severity of autonomic dysautonomia [13], we assessed the relationship between polyalanine expansion length and intellectual indexes using Pearson's correlations in the PARM subgroup $(\mathrm{n}=27)$. All tests were two-tailed and conducted at a $5 \%$ significance level.

\section{Results}

The study included 34 consecutive patients of mean (SD) age of 7.8 (3.8) years, ranging from 4 to 16 years and 6 months. Table 1 summarizes patients' sociodemographic, genetic and clinical characteristics. The distribution of males and females was equivalent (15 and 19 respectively) as well as the distribution of children younger than 6 years and those older (16 and 18 respectively). All patients had $P H O X-2 B$ mutations: 27 had PARMs [(mean length of polyalanine expansion was 6.2 (1.5)] and 7 had NPARMs. All had neonatal onset of CCHS except two in whom diagnosis was made at 18 months and 9 years of age. CCHS was isolated in 27 patients and associated to Hirschsprung disease in the others. All patients received night ventilation except one. The distribution of mask ventilation and tracheostomy ventilation was equivalent (16 and 17 respectively). Of note, 14 patients received mask ventilation since the time of diagnosis and were never tracheotomised. None required $24 / 24$ h ventilation or respiratory or cardiac pacemaker. One patient has been diagnosed with autism spectrum disorder. All lived at home with

Table 1 Data of the whole group of 34 CCHS patients, including genetic and clinical data (panel A) and intellectual indices (panel B)

\begin{tabular}{|c|c|c|c|}
\hline \multicolumn{4}{|l|}{ Panel A } \\
\hline \multicolumn{2}{|l|}{ Socio-demographic data } & \multicolumn{2}{|c|}{34 patients } \\
\hline \multicolumn{2}{|c|}{ Age, mean $\pm S D$, range, year:month } & \multicolumn{2}{|c|}{$7.8 \pm 3.8,4: 0-16: 6$} \\
\hline \multicolumn{2}{|c|}{ Younger than 6 years versus older than 6 years, $n$} & \multicolumn{2}{|c|}{16 versus 18} \\
\hline \multicolumn{2}{|c|}{ Male versus female, $\mathrm{n}$} & \multicolumn{2}{|c|}{15 versus 19} \\
\hline \multicolumn{4}{|l|}{ Genetic data } \\
\hline \multicolumn{2}{|c|}{ Patients with PARMs, n, genotype } & \multicolumn{2}{|c|}{$\begin{array}{l}27[n=8(20 / 25), n=11(20 / 26), n=7(20 / 27) \\
\quad \text { and } n=1(20 / 33)]\end{array}$} \\
\hline \multicolumn{2}{|l|}{ Patients with NPARMs, $\mathrm{n}$} & \multicolumn{2}{|c|}{7} \\
\hline \multicolumn{4}{|l|}{ Clinical data } \\
\hline \multicolumn{2}{|c|}{ Neonatal versus late-onset CCHS, n } & \multicolumn{2}{|c|}{32 versus 2 (diagnosed at 18 months and 9 years) } \\
\hline \multicolumn{2}{|c|}{ Isolated CCHS versus CCHS and HD, $n$} & \multicolumn{2}{|c|}{27 versus 7} \\
\hline \multicolumn{2}{|c|}{ Night ventilation versus No ventilation, $\mathrm{n}$} & \multicolumn{2}{|c|}{33 versus 1} \\
\hline \multicolumn{2}{|c|}{ Mask versus Tracheostomy ventilation, $\mathrm{n}$} & \multicolumn{2}{|c|}{16 (14 never tracheotomised) versus 17} \\
\hline \multicolumn{2}{|c|}{ Phrenic nerve or cardiac pacemaker, $\mathrm{n}$} & \multicolumn{2}{|l|}{0} \\
\hline \multicolumn{2}{|c|}{ Neonatal convulsions, $\mathrm{n}$} & \multicolumn{2}{|l|}{3} \\
\hline \multicolumn{2}{|l|}{ Special education program, $\mathrm{n}$} & \multicolumn{2}{|l|}{4} \\
\hline Panel B & $\mathrm{n}$ of patients tested & Mean \pm SD & $\begin{array}{l}95 \% \\
\text { confidence } \\
\text { interval }\end{array}$ \\
\hline Full-scale IQ & 34 & $82 \pm 20$ & 73-91 \\
\hline Verbal comprehension index & 33 & $88 \pm 21$ & 79-98 \\
\hline Visual-spatial index & 34 & $88 \pm 19$ & 79-96 \\
\hline Fluid reasoning index & 33 & $90 \pm 19$ & $82-99$ \\
\hline Working memory index & 31 & $81 \pm 13$ & $75-87$ \\
\hline Processing speed index & 31 & $77 \pm 19$ & $70-89$ \\
\hline
\end{tabular}


their families. Patients with CCHS had a poor academic record: although 30 of them attended regular school, 8 had repeated a school grade and 10 benefited the presence of a special needs assistant, whereas the remaining 4 required special education outside the regular system.

Intellectual measures included Full-scale Intelligence Quotient (FSIQ) and primary indices (Fig. 1). Half of the patients had normal intelligence, but for the whole group, mean (SD) individual FSIQ was 80 (20), being in the low average range (IQ 80-89). Similarly, mean scores of Verbal Comprehension Index (VCI), Visuo-Spatial Index (VSI), Fluid Reasoning Index (FRI) and Working Memory Index (WMI) were in the low average range; only mean score of Processing Speed Index (PSI) of 77 (19) was in the borderline range (IQ 69-79). Of importance, scores of WMI and PSI were significantly lower than those of VCI, VSI and FRI $(p<0.001$ FRI vs WMI, $p=0.004$ FRI vs PSI, $p=0.009$ VSI vs WMI, and $p<0.05$ for the others, Fig. 1).

\section{Association between intellectual indices and CCHS characteristics}

For the whole group, there was no association between intellectual indices and various $\mathrm{CCHS}$ characteristics, e.g. age group, gender, disease onset, presence of Hirschsprung disease.

Interestingly, mean scores of intellectual indices were found greater in patients with mask ventilation than in

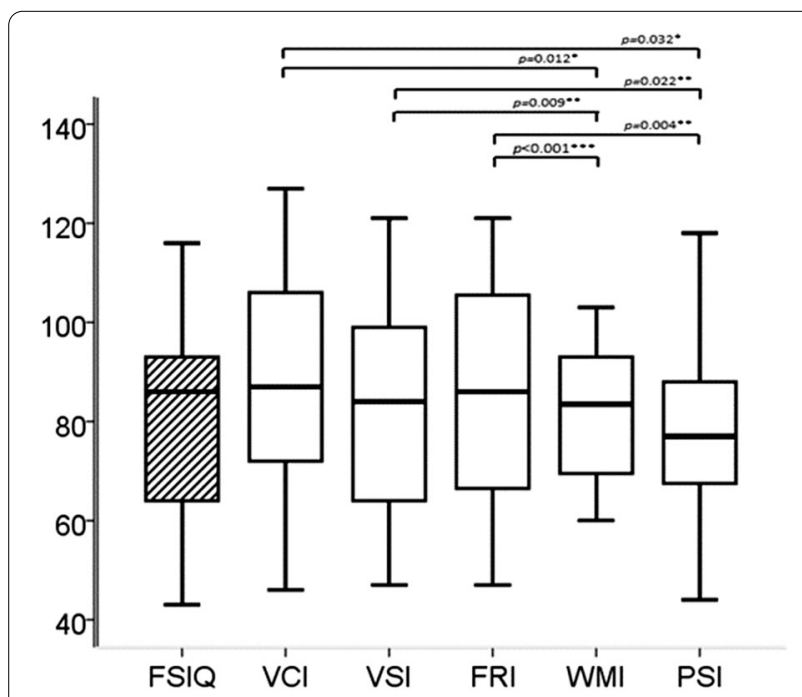

Fig. 1 Intellectual measures for the whole group $(N=34)$. Boxplots show the median in the middle, box lines show the first and third quartiles, and whiskers show the maximum and minimum values. FSIQ full-scale intellectual quotient, VCI verbal comprehension index, VSI visuo-spatial index, FR/ fluid reasoning index, WMI working memory index, PS/ processing speed index. ${ }^{*} p<0.05$; ${ }^{* *} p<0.01$; ${ }^{* * *} p<0.001$ (using paired $t$ tests) those with tracheostomy ventilation; a level of significance was obtained for FSIQ, VCI and PSI $(p=0.012$, 0.032 and 0.042 respectively, Fig. 2).

With regard to the genetic status, there was no significant differences in intellectual indices between PARM and NPARM groups and between NPARM, 20/25, 20/26 and 20/27 groups. However, when considering the PARM subgroup only, there was a statistically significant difference between subgroups for WMI as demonstrated by one-way ANOVA $(F(2,23)=4.9, p=0.022)$. A Tukey post hoc test showed that WMI was statistically greater in the $20 / 25$ group than in the $20 / 26$ group $(p=0.037)$ and in the $20 / 27$ group $(p=0.045)$. Most interestingly, there was a negative correlation between each of the intellectual indices and the number of polyalanine expansion. Correlation reached statistical significance for FRI and WMI $(r=-0.449, p=0.032$ and $r=-0.562, p=0.012$ respectively, Fig. 3).

\section{Discussion}

The present study showed that patients with CCHS had a mean Full-scale IQ in the low average range and that indexes of both working memory and processing speed were significantly lower when compared to the other Wechsler primary indices. These results were consistent with a few previous publications [17, 24, 30]. Of interest, there were two new findings. Full-scale IQ, and indexes of verbal comprehension and processing speed were found significantly greater in patients with mask ventilation than in those with tracheostomy ventilation. More importantly, in the patients with PARMs, intellectual indices showed negative correlations with the number of polyalanine expansion, with statistical significance reached for indexes of working memory and fluid reasoning. These data may suggest that both genetics and ventilation method may influence neurocognitive impairment in CCHS (Table 2).

These results should be understood in the following context. (1) Our study group was the largest reported thus far, investigated using the same standardized battery of cognitive tests. However, knowing the heterogeneity in clinical presentations in CCHS, the sample could still be considered as rather limited. (2) Our study group was the first reported with both patients using invasive ventilation and those using non-invasive ventilation. Invasive tracheostomy ventilation remained preferred for patients with CCHS in many parts of the world. Meanwhile, non-invasive ventilation has widely spread in Europe, mainly in some countries such as France, United Kingdom, Italy or Sweden. In these countries, during the last decade, mask ventilation has been initiated in patients with CCHS even during the neonatal period, so that some of them were never 


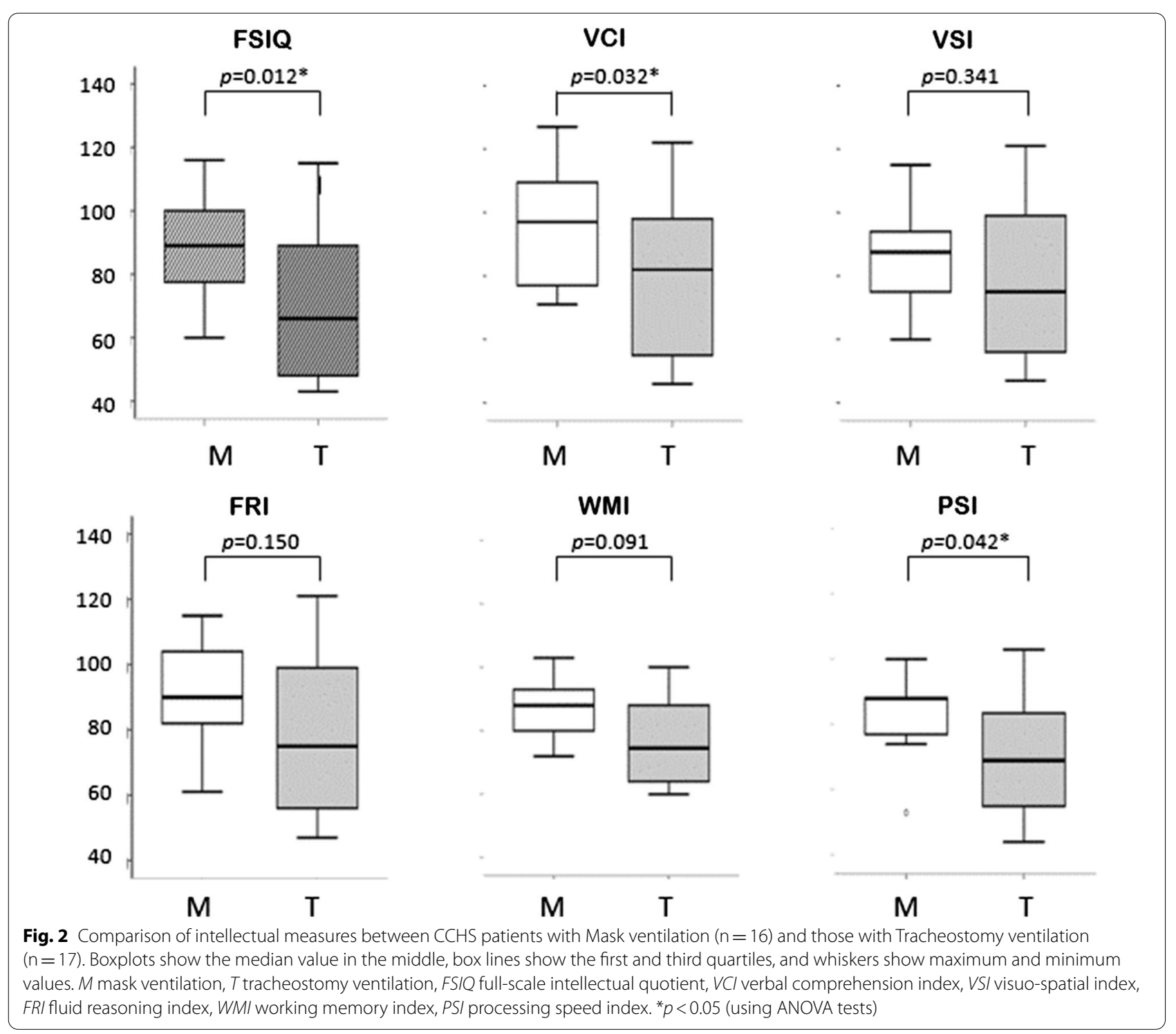

tracheotomised. (3) Although our study group included patients with CCHS, there were some recruitment biases. Health services for CCHS is organised as following in France: a national protocol of diagnosis and management of CCHS serves as guidelines [27], patients are managed by physicians near their place of residence and regularly assessed at the national centre of reference in Paris. This could explain the high proportion of patients with NPARMs in our study group (20\% instead of the less than $10 \%$ in published cohorts [28]). However, it was unlikely that this had impacted our overall results as there were no significant differences in intellectual measures between PARM and NPARM groups. (4) There was no matched comparison control group and cognitive assessments were not blind to diagnosis, although the neuropsychologist was blind to genetic data at the time of investigation.

Most of our patients with CCHS attended normal school, but many had repeated a school grade or required special education programs. Our results showed that half of them had normal intelligence but a broad variability of intellectual test results was observed. Interestingly, we found that both processing speed and working memory were significantly more affected than the other domains of cognition. Similar findings have been previously reported in school-age children with CCHS [30]. Processing speed refers to the speed with which one can complete simple cognitive tasks automatically and accurately as possible and move to the following one. Working memory is a master cognitive function which temporarily 


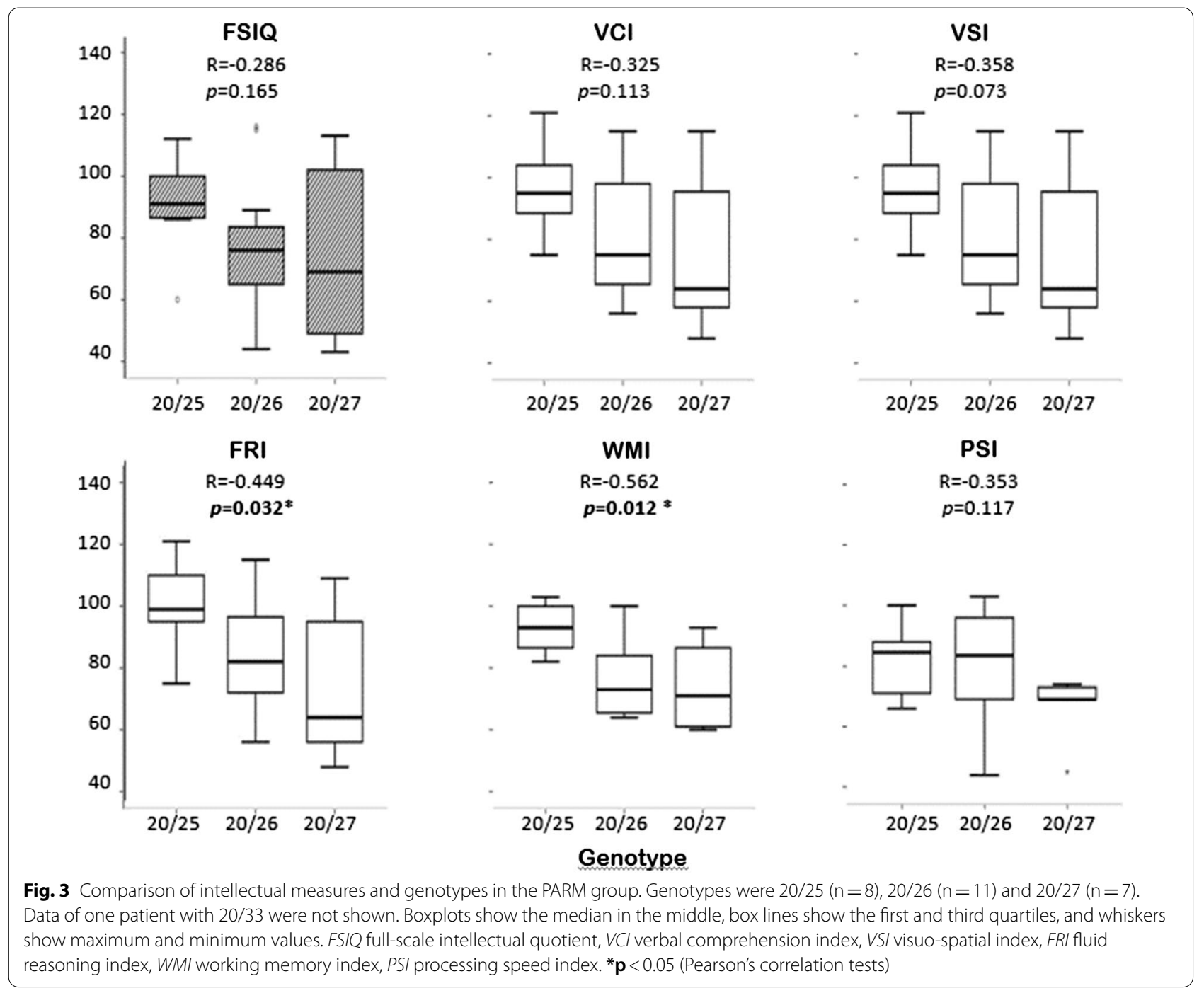

Table 2 Comparison of intellectual indices between subgroups of CCHS patients using Mask ventilation versus Tracheostomy ventilation

\begin{tabular}{llllll}
\hline & Mask $(\mathbf{n}=\mathbf{1 6})$ & Trach $(\mathbf{n}=\mathbf{1 7})$ & Mean difference & $\mathbf{9 5 \%} \mathbf{C l}$ of the difference & $\boldsymbol{p}$ \\
\hline Age (years) & $8.2 \pm 3.7(n=16)$ & $9.5 \pm 3.4(n=17)$ & -1.2 & $-3.8 ;-0.7$ & 0.053 \\
FSIQ & $89 \pm 17(n=16)$ & $70 \pm 23(n=17)$ & 19 & $4 ; 34$ & $\mathbf{0 . 0 1 2 ^ { * }}$ \\
VCI & $95 \pm 18(n=15)$ & $78 \pm 24(n=17)$ & 17 & $2 ; 33$ & $-8 ; 22$ \\
VSI & $86 \pm 17(n=16)$ & $79 \pm 24(n=17)$ & 7 & $-4 ; 27$ & $0.032^{*}$ \\
FRI & $91 \pm 15(n=13)$ & $79 \pm 25(n=17)$ & 11 & $-2 ; 20$ & 0.150 \\
WMI & $86 \pm 10(n=14)$ & $77 \pm 15(n=16)$ & 9 & $0.5 ; 27$ & 0.094 \\
PSI & $84 \pm 14(n=15)$ & $70 \pm 17(n=16)$ & 14 & & $\mathbf{0 . 0 4 2 *}$ \\
\hline
\end{tabular}

Data are mean $\pm S D ; n$ is the number of patients tested

FSIQ full-scale intellectual quotient, VCI verbal comprehension index, VSI visuo-spatial index, FRI fluid reasoning index, WMI working memory index, PSI processing speed index

${ }^{*} p<0.05$ (using ANOVA tests) 
maintains focus on new incoming information before it is processed by the central executive. Working memory is often associated with attention and executive functioning capacities [2]. Research has long showed relationships between processing speed and working memory capacities: indeed, individuals who can process information rapidly do not have to maintain it long in the working memory; conversely, those who process slowly will overload the working memory which can store a limited amount of information for short periods of time only. Different models have been proposed to shed light on the nature of complex interactions between processing speed and working memory and between these with other dimensions such as attention $[5,10]$. In all cases, limitations in processing speed and working memory resulted in significant delays in learning processes such as reading, mathematics and expression.

Causes underlying neurocognitive impairment in CCHS have been hypothesized but remained unfully investigated. Decades of research have shown the impacts of various sensory nervous system dysfunctions in learning difficulties. These approaches which are of high clinical relevance in many conditions may prevail in CCHS also. Indeed, the slowness observed in patients with CCHS has been suggested to be caused by visuo-spatial disorders. Patients with CCHS poorly performed visualmotor integration test, only two out of 11 of them were able to score at greater than the 50th percentile of agematched subjects [24]. Ocular disorders are a prominent feature of CCHS, found in as many as $90 \%$ of the patients. They mainly include pupillary defects and accommodative insufficiency as a result of ocular dysautonomia [18]. Most of the patients require corrective glasses or lenses and orthoptic rehabilitation. Whether there is additional dysfunction of the central visual pathways and of related brainstem nuclei has not been investigated yet. Moreover, an amount of literature has shown that reduced processing speed and working memory were associated with language disabilities [10]. In the neonatal period, patients with CCHS often have poor oral sphere motor capacities that affect ability to swallow, to eat then to speak. Vocabulary is developed through social interactions and experiencing new situations. Communication problems often result in deficits in vocabulary skills. Interestingly, the present study showed that patients with tracheostomy had poorer verbal comprehension and lower processing speed than those with mask ventilation. Indeed, tracheostomy ventilation is the only secure mode of ventilation used in CCHS patients with severe clinical presentations and associated co-morbidities. The latter are likely confounding factors leading to poor neurocognition. But having a tracheostomy may be an additional risk factor for greater speech and language delays despite specific therapies and further reduced communication options [25]. In this context, our results may suggest that mask ventilation should be preferred whenever possible in terms of safety, because the integrity of the oral-tracheal sphere may favour the subsequent development of speech and language.

Research has also shown that recurrent hypoxia and/ or hypercapnia can play a deleterious role in brain development, mainly in the first years of life, as previously reported in prematurity or congenital heart defects $[6$, 19]. But relationships between neurocognition and severity of respiratory deficits have not been demonstrated in CCHS [30]. Knowing the role of central autonomic networks on brain functioning, one may wonder in which extent CCHS-related autonomic dysfunction may impact on the modulation of brain development and plasticity, especially during critical periods of childhood. Of great interest, our present study is the first to show negative correlations between intellectual measures and the number of polyalanine expansions, with significance obtained for indexes of working memory and fluid reasoning. Before definitive conclusions can be sought, these results need to be confirmed in larger samples of patients with CCHS. Brain imaging have shown that some brain structures known as involved in neurocognition such as the caudate nucleus, the hippocampus or the ventral medial prefrontal cortex were smaller in CCHS subjects than in the controls $[11,12]$. Moreover, although overall cerebral blood flow was increased in CCHS, there were large regional variations with low blood flow especially in areas involved in autonomic regulation. This may reflect vascular alterations or impaired autonomic regulation in these areas $[7,8]$. Therefore, one may speculate on putative relationships between central autonomic dysfunction, brain plasticity and neurocognitive deficiencies in CCHS.

\section{Conclusion}

Although rare patients may have remarkable achievements, our findings confirm the importance of neurocognitive symptoms in the neonatal and childhood CCHS. They further suggested that both genetic and ventilation method were involved in the physiopathology of the impaired neurocognition. Further investigations are required to explore and better understand the insights of complex physiopathological processes. Learning difficulties in children with CCHS could be explained by the multiplicity and importance of cognitive deficits, even in those with normal intelligence. They significantly impacted on academic course and social interaction. Assessments of neurocognitive capacities should be performed at early ages and repeated regularly in order to detect subtle deficits and tailor re-educative programs. Remedial plans for improvement of various cognitive 
dimensions should be investigated. Children with CCHS require close monitoring of ventilatory status and general health and deserve more specialized adaptation of learning processes. Personalized medicine is likely the key concept to ensure academic and social achievements for the patients with CCHS.

\begin{abstract}
Abbreviations
CCHS: Congenital Central Hypoventilation Syndrome; Cl: Confidence interval; FRI: Fluid reasoning index; FSIQ: Full-scale IQ; HD: Hirschsprung disease; IQ: Intelligence quotient; NPARM: Non polyalanine repeat mutation; PARM: PolyAlanine repeat mutation; PHOX-2B: Paired like homeobox $2 \mathrm{~b}$ gene; PSI: Processing speed index; VCl: Verbal comprehension index; VSI: Visuo-spatial index; WISC: Wechsler Intelligence Scale for Children; WMI: Working memory index; WPPSI: Wechsler for Preschool and Primary Scale for Intelligence.
\end{abstract}

\section{Acknowledgements}

We thank all the children and their families for participating in the study. We thank Jessica Save and Anne Wallet (psychologists) for the discussions.

\section{Authors' contributions}

HT designed the study, performed data analysis and critically revised the manuscript. PB performed the neurocognitive tests and related analysis, revised the manuscript. FH performed data analysis, drafted and revised the manuscript. All authors contributed to and have approved the final manuscript. All authors read and approved the final manuscript.

\section{Funding}

This work did not receive any external funding.

\section{Availability of data and materials}

Availability of data and materials is on request.

\section{Ethics approval and consent to participate}

This retrospective study obtained ethics approval from the University Hospital Robert Debré Institutional Review Board. All families gave consent to publication of results under an aggregated form.

\section{Consent for publication}

All authors consent for publication.

\section{Competing interests}

The authors have no competing interests.

\section{Author details}

${ }^{1}$ Centre de référence de Maladies Respiratoires Rares Syndrome d'Ondine, Hôpital Universitaire Robert Debré, 48 Boulevard Sérurier, 75019 Paris, France. ${ }^{2}$ Université de Paris, 10 avenue de Verdun, 75010 Paris, France.

Received: 13 May 2020 Accepted: 26 October 2020

Published online: 17 November 2020

\section{References}

1. Amiel J, Laudier B, Attié-Bitach T, Trang H, de Pontual L, Gener B, Trochet D, Etchevers H, Ray P, Simonneau M, Vekemans M, Munnich A, Gaultier $C$, Lyonnet S. Polyalanine expansion and frameshift mutations of the paired-like homeobox gene PHOX2B in congenital central hypoventilation syndrome. Nat Genet. 2003;33:1-3.

2. Baddeley A, Della SS. Working memory and executive control. Philos Trans R Soc Lond B Biol Sci. 1996;351 (1346):1397-403 (discussion 1403-4).

3. Baddeley A. The fractionation of working memory. Proc Natl Acad Sci USA. 1996;93(24):13468-72.

4. Charnay AJ, Antisdel-Lomaglio JE, Zelko FA, Rand CM, Le M, Gordon SC, Vitez SF, Tse JW, Brogadir CD, Nelson MN, Berry-Kravis EM,
Weese-Mayer DE. Congenital central hypoventilation syndrome: neurocognition already reduced in preschool-aged children. Chest. 2016;149(3):809-15.

5. Giofrè $\mathrm{D}$, Cornoldi $C$. The structure of intelligence in children with specific learning disabilities is different as compared to typically development children. Intelligence. 2015;52:36-43.

6. Hövels-Gürich H. Psychomotorische und kognitive Entwicklung und Lebensqualität bei Kindern und Jugendlichen mit angeborenem Herzfehler [Psychomotor and cognitive development and quality of life in children and adolescents with congenital heart defect]. Klin Padiatr. 2019;231(4):183-90. https://doi.org/10.1055/a-0942-1756.

7. Kumar R, Macey PM, Woo MA, Alger JR, Harper RM. Diffusion tensor imaging demonstrates brainstem and cerebellar abnormalities in congenital central hypoventilation syndrome. Pediatr Res. 2008;64:275-80.

8. Kumar R, Woo MS, Macey PM, Woo MA, Harper RM. Progressive gray matter changes in patients with congenital central hypoventilation syndrome. Sleep Med. 2010;11:589-90.

9. Lagercrantz R, Kristian BK, Lagercrantz H, Markström A, Böhm B. Neurocognitive function and quality of life with congenital central hypoventilation syndrome. J Sleep Med Disord. 2020;6(1):1097-102.

10. Leonard LB, Ellis Weismer S, Miller CA, Francis DJ, Tomblin JB, Kail RV. Speed of processing, working memory, and language impairment in children. J Speech Lang Hear Res. 2007;50(2):408-28.

11. Macey PM, Kumar R, Ogren JA, Woo MA, Harper RM. Altered cerebral blood flow in a patient with congenital central hypoventilation syndrome. Pediatr Res. 2012;71(6):701-6.

12. Macey PM, Richard CA, Kumar R, Woo MA, Ogren JA, Avedissian C, Thompson PM, Harper RM. Hippocampal volume reduction in congenital central hypoventilation syndrome. PLoS ONE. 2009;4:e6436.

13. Matera I, Bachetti T, Puppa F, Di Bucca M, Morandi F, Casiraghi GM, et al. PHOX2B mutations and polyalanine expansions correlate with the severity of the respiratory phenotype and associated symptoms in both congenital and late onset central hypoventilation syndrome. J Med Genet. 2004;41(373-80):59.

14. Marcus $\mathrm{CL}$, Jansen MT, Poulsen MK, et al. Medical and psychosocial outcome of children with congenital central hypoventilation syndrome. J Pediatr. 1991;119:888-95.

15. Mellins RB, Balfour HH Jr, Turino GM, Winters RW. Failure of autonomic control of ventilation (Ondine's course). Medicine. 1970;149:487-526.

16. Montirosso R, Morandi F, D’Aloisio C, Berna A, Provenzi L, Borgatti R. International classification of functioning, disability and health in children with congenital central hypoventilation syndrome. Disabil Rehabil. 2009;31(Suppl 1):S144-52.

17. Oren J, Kelly DH, Shannon DC. Long-term follow-up of children with congenital central hypoventilation syndrome. Pediatrics. 1987:80:375-80.

18. Patwari PP, Stewart TM, Rand CM, Carroll MS, Kuntz NL, Kenny AS, Brogadir $C D$, Weese-Mayer DE. Pupillometry in congenital central hypoventilation syndrome (CCHS): quantitative evidence of autonomic nervous system dysregulation. Pediatr Res. 2012;71(3):280-5.

19. Raman L, Georgieff MK, Rao R. The role of chronic hypoxia in the development of neurocognitive abnormalities in preterm infants with bronchopulmonary dysplasia. Dev Sci. 2006;9(4):359-67. https://doi.org/1 0.1111/j.1467-7687.2006.00500.x (PMID: 16764609).

20. Ruof H, Hammer J, Tillmann B, Ghelfi D, Weber P. Neuropsychological, behavioral, and adaptive functioning of Swiss children with congenital central hypoventilation syndrome. J Child Neurol. 2008;23(11):1254-9.

21. Sasaki A, Kanai M, Kijima K, Akaba K, Hashimoto M, Hasegawa H, Otaki S, Koizumi T, Kusuda S, Ogawa Y, Tuchiya K, Yamamoto W, Nakamura T, Hayasaka K. Molecular analysis of congenital central hypoventilation syndrome. Hum Genet. 2003;114(1):22-6.

22. Seijas-Gomez R, Esteso-Orduna B, Melero-Llorente J, Fournier-Del Castillo MC. Clinical and neuropsychological characteristics in congenital central hypoventilation syndrome. Rev Neurol. 2018;66(9):303-7.

23. Shimokaze T, Sasaki A, Meguro T, Hasegawa H, Hiraku Y, Yoshikawa T, Kishikawa Y, Hayasaka K. Genotype-phenotype relationship in Japanese patients with congenital central hypoventilation syndrome. J Hum Genet. 2015;60(9):473-7.

24. Silvestri JM, Weese-Mayer DE, Nelson MN. Neuropsychologic abnormalities in children with congenital central hypoventilation syndrome. J Pediatr. 1992;120:388-93. 
25. Streppel M, Veder LL, Pullens B, Joosten KFM. Swallowing problems in children with a tracheostomy tube. Int J Pediatr Otorhinolaryngol. 2019;124:30-3.

26. Trang H, Dehan M, Beaufils F. The French congenital central hypoventilation syndrome registry: general data, phenotype, and genotype. Chest. 2005; 127(1):72-9.

27. Trang H. Le Protocole National de Diagnostic et de Soins du Syndrome d'Ondine 2018. https://www.has-sante.fr/jcms/c_2829806/fr/syndromed-ondine-pnds (French).

28. Trang H, Samuels M, Ceccherini I, Frerick M, Garcia-Teresa MA, Peters J, Schoeber J, Migdal M, Markstrom M, Ottonello G, Piumelli R, Estevao MH, Senecic-Cala I, Gnidovec-Strazisar B, Pfleger A, Porto-Abal R, Katz-Salamon M. Guidelines for diagnosis and management of congenital central hypoventilation syndrome. Orphanet J Rare Dis. 2020;15:252.
29. Vanderlaan M, Holbrook CR, Wang M, Tuell A, Gozal D. Epidemiologic survey of 196 patients with congenital central hypoventilation syndrome. Pediatr Pulmonol. 2004;37:217-29.

30. Zelko FA, Nelson MN, Leurgans SE, Berry-Kravis EM, Weese-Mayer DE. Congenital central hypoventilation syndrome: neurocognitive functioning in school age children. Pediatr Pulmonol. 2010;45:92-8.

\section{Publisher's Note}

Springer Nature remains neutral with regard to jurisdictional claims in published maps and institutional affiliations.
Ready to submit your research? Choose BMC and benefit from:

- fast, convenient online submission

- thorough peer review by experienced researchers in your field

- rapid publication on acceptance

- support for research data, including large and complex data types

- gold Open Access which fosters wider collaboration and increased citations

- maximum visibility for your research: over $100 \mathrm{M}$ website views per year

At BMC, research is always in progress.

Learn more biomedcentral.com/submissions 